\title{
Mathematical Models of Throttle Elements of Gas-hydrodynamic Measuring Transducers
}

\author{
Yevhen Pistun, Halyna Matiko *, Hanna Krykh \\ Lviv Polytechnic National University, 12 Stepana Bandery St., Lviv, 79013, Ukraine
}

Received: February 01, 2019. Revised: April 02, 2019. Accepted: August 27, 2019.

(C) 2019 The Authors. Published by Lviv Polytechnic National University.

\begin{abstract}
This is a review article and it presents the flowrate characteristics of throttle elements used for measuring diagrams of transducers of fluids parameters. The review includes a wide range of research on the characteristics of incompressible and compressible fluids, Newtonian and Non-Newtonian fluids at the conditions of laminar, transient and turbulent flow through the channels of different cross-sections. The article considers equations for macroscopic flows. The theoretical equations for calculating the pressure drop for fluid flow in microchannels are presented. The conditions and the range of their application are presented for these equations. The results of experimental research of friction factor for compressible and incompressible fluids in microchannels of various sizes and shapes with smooth and rough surfaces are considered. The obtained results can be used for computer research of static and metrological characteristics of gas-hydrodynamic measuring transducers of specific physical and mechanical parameters of fluids.
\end{abstract}

Keywords: flowrate characteristic; capillary tube; constricting device; microchannel; measuring transducer; physical and mechanical parameters.

\section{Definition of the problem to be solved}

The automatic measuring and control systems of physical and mechanical parameters of fluids are used in many technological processes. The technical, economical and quality factors of production depend on them considerably. These parameters are density, dynamic and kinematic viscosity of gases and liquids, consistency index, plastic viscosity, yield stress, consistency index, flow behaviour index of Non-Newtonian fluid, volume and mass flowrates of fluid, etc. The primary measuring transducers and systems of continuous operation built on some sensing elements are used for their measuring [1], [2]. Particular attention should be paid to transducers with throttle sensing elements which have significant potential to solve measurement problems according to their constructive, working and economic characteristics [3].

The following throttle elements such as constricting devices or tubes of various configurations and shapes are often used for building the measuring transducers of physical and mechanical parameters of liquids and gases. The work of such sensing elements is based on the dynamic effects that arise during the gas or liquid flow through the throttle element. Such processes as flows throttling, jets interacting, vortex forming, transforming of laminar flow into turbulent one and vice versa, the effect of power, electric, magnetic fields on fluid flow and others are used to form primary signals. We offered to name the method of measuring the physical and mechanical parameters of liquids and gases based on the dynamic effects in the throttle elements as gas-hydrodynamic method. The measuring transducers are called gasdynamic if gas is the measuring fluid or hydrodynamic if liquid is the measuring fluid [3].

Synthesis of gas-hydrodynamic throttle measuring transducers or systems is based on their mathematical models which always contain the flowrate characteristics of the throttle elements used in the diagram [4]-[6]. If the transducer

\footnotetext{
${ }^{*}$ Corresponding author. Email address: halynamatiko@gmail.com
}

This paper should be cited as: Y. Pistun, H. Matiko, H. Krykh. Mathematical models of throttle elements of gashydrodynamic measuring transducers. Energy Engineering and Control Systems, 2019, Vol. 5, No. 2, pp. 94 - 107. https://doi.org/10.23939/jeecs2019.02.094 
contains only one throttle element, then its model is based on the flowrate characteristic of this element. Usually, transducers contain several different throttle elements that are connected in different diagrams [7]. Each of these elements works in different conditions. In addition they can vary during the work of the measuring transducer. Gashydrodynamic resistance of throttle elements, unlike the electric resistance, depends on many factors. Therefore, solving the problem of correct choice of the equations of the flowrate characteristics of each throttle element is very important for obtaining an adequate mathematical model of the measuring transducer of specific fluid parameter.

\section{Analysis of the recent publications and research works on the problem}

Mathematical models of gas-hydrodynamic measuring transducers are determined by lots of factors: the type and the number of throttle elements in the diagram, the way of their connection in the diagram [6]-[9], the type and the properties of the fluid (compressible, incompressible, Newtonian, non-Newtonian, etc.) [10], the power supply of the transducer (constant pressure, constant flowrate, constant pressure drop) [5], the type of output signal (pressure, pressure drop, flowrate). The mathematical model of the throttle measuring transducer depends on the values of these factors. Taking into account these factors each throttle element of the transducer is described by the flowrate characteristic that relates the fluid flowrate through the element with the upstream and downstream pressure. The flowrate characteristics of the throttle elements for a specific transducer also depend on the physical and mechanical parameters of the fluid, on fluid flow and the conditions for this flow, on the geometric and fitting dimensions of the throttles, on the material and quality of the throttle flowing surface, etc. [3]. Such a variety of throttle elements and their applications in gas-hydrodynamic measuring transducers has resulted in a large number of investigations into their flowrate characteristics at different working conditions. Especially great interest in the flow characteristics of liquids and gases in the throttling elements arose with the development of pneumatic and hydro-automatics. Thus, the problems of calculating the characteristics of pneumatic turbulent throttles are theoretically solved in [11], [13]. There are also considered the transient conditions from subsonic to supersonic flow in cylindrical tubes of a circular crosssection, as well as the flow characteristics of air, gases and liquids through laminar and combined throttles of different configurations.

The results of numerous theoretical and experimental studies of the flowrate characteristics of different types of throttles are presented in [14]-[17]. They are the basis for flowmeters of gases and liquids with different measuring ranges. The papers [18]-[21] are devoted to the analysis and experimental study of the flowrate characteristics of throttle elements of various types for different gases. Gas-dynamic throttle flowmeters of small- and micro- flowrates of gases were proposed and implemented on the basis of these characteristics, as well as analysers of gas mixtures composition. The paper [22] presents an approximate mathematical method for obtaining analytical relations between the pressure drop and the volumetric flowrate for the laminar flow regimes of Newtonian and power law fluids through symmetrically corrugated capillary fissures and tubes. The papers [23], [24] consider the flowrate characteristics of the circular tubes for the laminar flow of viscoplastic and pseudoplastic fluids with different rheological models.

The Hagen-Poiseuille equation [25] is traditionally used in order to build the mathematical models of capillary viscometers of liquids. It should be corrected for insufficiently long cylindrical circular tubes with the help of Couet and Gagenbach corrections [26]. In the paper [27] the flowrate characteristics for the tubes of a circular cross-section of finite length and for the turbulent throttles for the transient flow are corrected by the modelling method. The mathematical models of throttle transducers of viscosity and density of fluids are built on the basis of these flowrate characteristics.

During the last decades, study of the features of fluids flow in micro- and minichannels is of considerable interest. They are more often used in modern microfluidic devices and systems including measuring, as well as in technology, micro-chemical (MCS) and micro-electromechanical systems (MEMS) [25], [28]-[47]. Analytical and semi-analytical models [25]-[30], [40], [41], [43], [47] are developed to study the fluids flow in microchannels. Simulation methods and experimental methods for microflows are used in [31]-[36], [42], [45], [46]. In practice, mathematical modelling of measuring microdevices and systems is conveniently carried out with the help of engineering models. Thus, the hydrogasdynamics of laminar microchannels in micro-transducers of the fluids viscosity is usually described using the friction coefficient or the Poiseuille number. Many studies show that conventional laminar theory of incompressible and compressible fluids in ordinary-sized capillaries with smooth flow surfaces can predict single-phase flows in microchannels [32], [33], [37], [40], [46], [47]. According to another research of single-phase microfluids in circular channels and channels of the other cross-section shapes the friction factor and the Poiseuille number are higher or lower than those according to traditional theories [30], [34]-[36], [39]. 
The effects of compressibility and rarefaction on the local flow resistance of isothermal gas flow in circular microchannels for a wide range of working conditions have been numerically studied in detail in [30]. It was found that the friction factor is a function of the inlet Mach number, the Reynolds number and the length-diameter ratio of the channel. According to many experimental studies of hydrogasdynamics in microchannels the friction factor significantly depends on the relative roughness. It also affects the value of the Reynolds number, at which laminar flow changes into turbulent [30], [45].

\section{Formulation of the goal of the paper}

The goal of the paper is to analyse and to systematize the research of the flowrate characteristics of throttle elements as the main components of gas-hydrodynamic measuring transducers of physical and mechanical parameters of fluids - gases and liquids with different rheological behaviour. As a result it is necessary to determine the range of application of the equations for calculating the flow characteristics of Newtonian and non-Newtonian liquids and gases through the throttle elements of different configurations and sizes and to formulate the recommendations for their applying to build the measuring transducers of physical and mechanical parameters.

\section{Presentation and discussion of the research results}

\subsection{Mathematical models of throttle elements}

The most common sensing elements of throttle measuring diagrams are cylindrical tubes (capillaries) of different lengths with a circular cross-section, slit elements with a rectangular cross-section, thin-walled orifice plates, nozzles, etc. [11], [12]. Throttle elements are divided into laminar, turbulent and combined depending on the fluid flow through the throttle elements and its construction. The pressure losses in laminar throttles are caused by the friction between the layers parallel to the fluid flow direction. The fluid flow in turbulent throttles is accompanied by the layers mixing, velocity and pressure pulsations. The pressure losses are caused by the local resistance at the throttle inlet and outlet. Combined throttles work at any flow - laminar, transient or turbulent. The pressure drop across such throttles is caused both by local losses and friction. A long cylindrical tube with a large ratio of length to diameter with a laminar fluid flow is an example of a laminar throttle. A bore in a thin wall with a developed turbulent flow is a turbulent throttle. A short cylinder tube with laminar or transient or turbulent fluid flow is a combined throttle. Table 1 shows some examples of throttle elements.

Table 1. Examples of throttle elements.

\begin{tabular}{|c|c|c|c|}
\hline $\begin{array}{c}\text { Type of throttle } \\
\text { elements }\end{array}$ & $\begin{array}{c}\text { Name of throttle } \\
\text { elements }\end{array}$ & Fluid flow & Laminar \\
\hline Laminar & Long capillary tube & Orifice plates, nozzles & Transient or turbulent \\
\hline Turbulent & Short capillary tube & $\begin{array}{c}\text { Laminar or transient } \\
\text { or turbulent }\end{array}$ \\
\hline Combined & C
\end{tabular}

Throttle elements are described by the flowrate characteristic which relates the flowrate of the fluid through the element with upstream and downstream pressure (pressure drop across the element), as well as with its constructive characteristics and physical and mechanical parameters of the fluid. Each type of throttle element has its own flowrate characteristic.

Let's consider the mathematical models of the presented types of throttle elements. Experimental studies of the flowrate characteristic of a laminar throttle element in the form of ordinary-sized cylindrical capillary tube for incompressible Newtonian fluid are initiated by Hagen and Poiseuille [25], [29]. Theoretically the equation that relates the flowrate and the pressure drop is obtained by Stokes i Hagenbach [25]:

$$
Q=\frac{\pi d^{4} \rho\left(P_{1}-P_{2}\right)}{128 L \mu}=\frac{\pi d^{4} \rho \Delta P}{128 L \mu},
$$


where $Q$ is the mass flowrate through the tube; $P_{1}$ and $P_{2}$ is the upstream pressure and the downstream pressure of the throttle respectively; $\Delta P=P_{1}-P_{2}$ is the pressure drop across the length of the tube; $d$ is the diameter of the tube; $L$ is the length of the tube; $\mu$ is the fluid dynamic viscosity; $\rho$ is the fluid density. It should be noted that for the specific throttle design and mode parameters the flowrate characteristic (1) is linear.

The flowrate characteristics of long capillary tubes for non-Newtonian fluids are obtained on the basis of a general equation [23]

$$
Q=\frac{\pi d^{3} \rho}{8 \tau_{w}^{3}} \int_{0}^{\tau_{w}} \tau^{2} f(\tau) d \tau
$$

where $\tau$ is the tangential shear stress; $\tau_{w}=\Delta P d / 4 L$ is the tangential shear stress on the wall; $\dot{\gamma}=f(\tau)$ is the rheological model of the fluid that relates the shear rate $\dot{\gamma}$ with the shear stress $\tau$.

Equation (2) is universal for liquids with various rheological behaviours (including the Newtonian liquid) [23]. For example, the equation of the flowrate characteristic of a long capillary tube for the non-Newtonian viscoplastic liquid which is described by the Bingham model $\dot{\gamma}=f(\tau)=\left(\tau-\tau_{0}\right) / \eta$ can be written as

$$
Q=\frac{\pi d^{3} \rho}{8} \frac{\Delta P d}{16 L \eta}\left(1-\frac{4}{3} c+\frac{1}{3} c^{4}\right)
$$

where $\eta$ is the plastic viscosity of the liquid; $c=\frac{4 L \tau_{0}}{\Delta P d}=\frac{\tau_{0}}{\tau_{w}}$ is the ratio of yield stress $\tau_{0}$ to the tangential shear stress $\tau_{\mathrm{w}}$ on the wall. The Bingham plastic flow in the tube occurs only when the shear stress $\tau_{0}<\tau<\tau_{w}$. The equation of the flowrate characteristic of a tube with a circular cross-section for a pseudoplastic liquid which is described by a power law rheological model $\dot{\gamma}=(\tau / K)^{1 / n}$ can be written as

$$
Q=\frac{\pi d^{3} \rho}{8} \frac{n}{3 n+1}\left(\frac{\Delta P d}{4 L K}\right)^{1 / n}
$$

where $K, n$ are the fluid rheological parameters: consistency index and flow behaviour index. The equation of the flowrate characteristic for liquid with a generalized rheological Herschel-Bulkley model $\dot{\gamma}=\left[\left(\tau-\tau_{0}\right) / K\right]^{1 / n}$ can be written as [24]

$$
Q=\frac{\pi d^{3} \rho}{8} \frac{n}{(3 n+1)(2 n+1)(n+1)}\left(\frac{\Delta P d}{4 L K}(1-c)\right)^{1 / n} \cdot\left[\left(2 n^{2}\left(1-c^{3}\right)-n c(1+2 c)+3 n+1-c\right)\right] .
$$

For $c=0$, we obtain the equation (4) of the flowrate characteristic of the power law liquid, and for $n=1$ the equation (3) of the flowrate characteristic of Bingham plastic liquid. Many other rheological models of non-Newtonian fluids are used in addition to the presented above. For some of them the equation of flowrate characteristics of long capillary tubes can be obtained in analytical or numerical form [23], [24]. Usually, the flowrate characteristics of long capillary tubes for non-Newtonian fluids are nonlinear.

It should be noted that equations (1)-(5) are derived taking into account many assumptions. The main of them are: the fluid flow is stable, laminar, axisymmetric; the tube is long enough and its end effects can be neglected; the fluid is incompressible; fluid properties (i.e. density and viscosity) don't depend on pressure and don't change in time; the fluid flow is isothermal; there is no slip at the wall of the tube and the velocity at the tube-liquid interaction is zero; the radial velocity and the radial pressure tube gradient equal zero. These assumptions are justified for many situations, such as the flow of water, organic and generally single-phase liquids in ordinary-sized capillaries and tubes [25]. 
The mass flowrate of fluids through a rectangular slit with height $h$ formed by flat parallel plates of width $w$ is determined by the equations obtained for the most of assumptions as for a long capillary tube of circular cross-section [11], [23]

for Newtonian fluid:

$$
Q=\frac{h^{3} w \rho \Delta P}{12 L \mu}
$$

for power law fluid:

$$
Q=\frac{h^{2} w \rho n}{2(2 n+1)}\left(\frac{\Delta P h}{2 L K}\right)^{1 / n},
$$

for Bingham plastic fluid:

$$
Q=\frac{h^{3} w \rho \Delta P}{12 L \eta}\left(1-\frac{3}{2} c+\frac{1}{2} c^{3}\right)
$$

It should be noted that equations (6)-(8) are valid provided that the height-width ratio $a=h / w<<1$.

The mass flowrate of the Newtonian liquid for a ring slit is described by the equation [11]

$$
Q=\frac{\rho h^{3} d \Delta P}{6 L \mu}
$$

where $d=\left(d_{1}+d_{2}\right) / 2$ is the average diameter of the ring slit; $d_{1}$ is the inner diameter of the outer tube; $d_{2}$ is the outer diameter of the inner tube; $h=\left(d_{1}-d_{2}\right) / 2$ is the dimension of the slit; $L$ is the length of the slit.

Let's consider the equation of flowrate characteristics of a long capillary tube for compressed flow. The average density $\rho$ in equation (1) is determined by the average value $\rho_{a v}$ which is calculated by the arithmetic mean absolute pressure $P=\left(P_{1}+P_{2}\right) / 2$ at the inlet and outlet of the throttle:

$$
\rho_{a v}=\frac{P}{R T}=\frac{P_{1}+P_{2}}{2 R T}
$$

where $R$ is the gas constant; $T$ is the average absolute temperature of gas in the throttle. Then the flowrate characteristic of long capillary tube for subsonic isothermal flow of compressible fluid is described by the equation [11], [12]

$$
Q=\frac{\pi d^{4}\left(P_{1}^{2}-P_{2}^{2}\right)}{256 L \mu R T}
$$

Equation (11) is used at low pressure drop across the throttle and relatively small throttle diameters when the gas density changes are insignificant and the gas density $\rho$ is assumed to be constant and equal to the mean value $\rho_{a v}$ [13]. If the pressure drop across the throttle increases but the gas flow remains laminar then one can use the following equation for the flowrate characteristic [11]:

$$
Q=\frac{4 \pi L \mu}{\ln \left(P_{1} / P_{2}\right)}\left[\sqrt{1+\frac{\ln \left(P_{1} / P_{2}\right) d^{4}\left(P_{1}^{2}-P_{2}^{2}\right)}{512 L^{2} \mu^{2} R T}}-1\right] .
$$

In practice, the state equation with compressibility factor $Z$ is used to describe the deviation of a real gas from ideal gas behaviour. The compressibility factor is found experimentally for each gas. Then average gas density $\rho_{a v}$ is determined taking into account the compressibility factor $Z$

$$
\rho_{a v}=\frac{P}{Z R T}=\frac{P_{1}+P_{2}}{2 Z R T}
$$


If the average gas density at working conditions is determined by equation (13) and reduced to the normal conditions, then a more accurate flowrate characteristic for a long capillary tube is obtained:

$$
Q=\frac{\pi d^{4} \rho_{N} T_{N}\left(P_{1}^{2}-P_{2}^{2}\right)}{256 L \mu Z T P_{N}},
$$

where $\rho_{N}, T_{N}, P_{N}$ are the density, absolute temperature and absolute pressure at normal conditions, respectively. The compressibility factor $Z$ is taken as a constant at specified changes of pressure in capillary tube. The other equations of flowrate characteristics of capillary tubes for compressible fluids are also presented in [19]-[21]:

$$
\begin{gathered}
Q=\frac{\pi d^{4} P_{2}}{128 L \mu} \rho_{2} \ln \left(\frac{P_{1}}{P_{2}}\right), \\
Q=\frac{\pi d^{4} P_{2}}{128 L \mu} \rho_{N} \frac{\ln \left(P_{1} / P_{2}\right)}{1-(\gamma-1) e^{\frac{2-\gamma}{\gamma}} \ln \left(P_{1} / P_{2}\right)}, \\
Q=\frac{\pi d^{4} \rho_{2}}{128 L \mu} \Delta P,
\end{gathered}
$$

where $\gamma$ is the specific heats ratio; $\rho_{2}$ is the gas density at the outlet of the throttle. The errors of the flowrate defined by the equations (15)-(17) depend on the geometric dimensions of the tubes, the pressure drop across the tube and the absolute values of pressure.

The mass flowrate $Q$ of incompressible Newtonian fluid for another type of throttle elements - turbulent ones, such as orifice plates, nozzles, etc. is related with the pressure drop $\Delta P$ across the throttle by the equation [14]-[16]

$$
Q=\alpha F(2 \Delta P \rho)^{0.5},
$$

where $\rho$ is the fluid density; $\alpha$ is the flowrate coefficient; $F=\pi d^{2} / 4$ is the area of the cross-section of throttle channel; $d$ is the diameter of the cross-section of throttle channel. The flowrate coefficient $\alpha$ for a turbulent throttle is constant if the Reynolds number $R e=4 Q / \pi d \mu$ varies in the range from the minimum to the maximum limit values, and depends on the design of the constricting device, in particular on the relative area $m=(d / D)^{2}$, where $D$ is the diameter of a conduit, on the thickness of the orifice plate, on the profile of the cross-section of the throttle, on the inlet and the outlet edge of the throttle. In [27] the fluid flow was investigated through an orifice plate with a bore $0.5-1.5 \mathrm{~mm}$ and thickness $0.1-0.5 \mathrm{~mm}$ and the following equation was obtained:

$$
\Delta P=g \frac{Q^{2}}{2 \rho F^{2}} .
$$

It is similar to the equation (18) obtained on the basis of the Bernoulli equation. The coefficient $g$ with a confidence probability of 0.95 is equal to $1.10 \pm 0.062$. The regression equation (19) can be used for the transient flow from laminar to turbulent at a number $R e$ from 2000 to 10000 .

It should be noted that flow turbulence may occur even in sufficiently long capillary tubes if pressure drop across the throttle is significant. On the other hand the fluid flow is turbulent even at low pressure drops in the short channels and in the bores in the thin wall [13]. In these cases the mass flowrate through the hydraulic throttle is generally determined by the equation (18). The flowrate coefficient $\alpha$ in this equation depends on the throttle configuration as well as on Reynolds number $R e$.

Let's consider the flow of compressible fluid through a turbulent throttle - the orifice plate assuming the flow is adiabatic. For subsonic flow of gas when 


$$
\frac{P_{2}}{P_{1}}>\left(\frac{2}{\gamma+1}\right)^{\frac{\gamma}{\gamma-1}}
$$

the mass flowrate of gas through a bore is described by Saint-Venant and Wantzel equation [12], [13]

$$
Q=\alpha F\left(\rho_{1} P_{1} \frac{2 \gamma}{\gamma-1}\right)^{0.5}\left[\left(\frac{P_{2}}{P_{1}}\right)^{\frac{2}{\gamma}}-\left(\frac{P_{2}}{P_{1}}\right)^{\frac{\gamma+1}{\gamma}}\right]^{0.5},
$$

where the flowrate coefficient $\alpha$ characterizes the pressure loss on friction, on the narrowing (expansion) of the gas flow, heat transfer and other unconsidered factors; $\gamma$ is the specific heats ratio; $\rho_{1}$ is the gas density at the throttle inlet.

For the supersonic gas flow when the condition is fulfilled

$$
0<\frac{P_{2}}{P_{1}}<\left(\frac{2}{\gamma+1}\right)^{\frac{\gamma}{\gamma-1}}
$$

the mass flowrate of gas through a bore is described by an equation [12]

$$
Q=\alpha F\left(\rho_{1} P_{1} \frac{2 \gamma}{\gamma+1}\right)^{0.5}\left(\frac{2}{\gamma+1}\right)^{\frac{1}{\gamma-1}},
$$

the symbols in (22), (23) corresponds to (21).

For the stable subsonic turbulent gas flow through an orifice plate at low pressure drop when the gas compressibility can be neglected ( $\rho=$ const), the mass flowrate of gas is determined by the simplified formulas [11]

$$
\begin{aligned}
& Q=\alpha F\left(2 \Delta P \rho_{1}\right)^{0.5}, \\
& Q=\alpha F\left(2 \Delta P \rho_{2}\right)^{0.5},
\end{aligned}
$$

where $\Delta P=P_{1}-P_{2}$ is the difference of absolute pressures upstream and downstream the throttle; $\rho_{1}, \rho_{2}$ are the gas densities upstream and downstream the throttle.

For the supersonic gas flow through a throttle with a relatively short length the approximate equation of the flowrate characteristic is [47]

$$
Q=\alpha F P_{1}\left(2 R T_{2}\right)^{-0.5},
$$

where $T_{2}$ is the absolute gas temperature downstream the throttle.

In practice of measuring the flow of compressed fluids with turbulent flow by means of pressure differential devices the following equation is used for standard constricting devices (orifice plates, nozzles, Venturi nozzles) [15], [16], [17]:

$$
Q=\alpha \varepsilon F\left(2 \Delta P \rho_{1}\right)^{0.5},
$$

where $\varepsilon$ is the expansibility factor which takes into account the change in fluids density in the throttle element. In general, the factor $\varepsilon$ depends on the design of the constricting device, the pressure drop $\Delta P$ across it, as well as on the absolute pressure $P_{1}$ and the specific heats ratio $\gamma$.

It should be added that special standard constricting devices (orifice plates with tapered inlet, cylindrical nozzles, "quarter of a circle" nozzles, double orifice plates, wear-resistant orifice plates, segmental orifice plates) are also used 
to measure the flow for a wide range of numbers $R e$ from 40 to 300000 . These constricting devices are allowed to measure the flow only in the range of Reynolds number $R e$ for which the flowrate coefficient $\alpha$ is constant in equation (27) [49]. The value of the coefficient $\alpha$ depends on the type of constricting device as well as its relative area.

Non-standard constricting devices are also used for constructing transducers measuring flowrate. So, the paper [50] presents the watch stones with a bore of a complex form made of synthetic corundum for measuring the microflow of gases. The research of stones with nominal diameters $0.08 \mathrm{~mm}, 0.09 \mathrm{~mm}$ and $0.11 \mathrm{~mm}$ for air, helium and carbon dioxide showed that the following equation is adequate to describe their flowrate characteristics:

$$
Q=\alpha F\left(2 \Delta P \rho_{1}\right)^{0.5} \cdot\left(\frac{P_{2}}{P_{1}}\right)^{\frac{1}{2 \gamma}},
$$

where the subscripts 1 and 2 correspond to the parameters at the throttle inlet and outlet as for the previous formulas. It has been found experimentally that the flowrate coefficient $\alpha$ in equation (28) depends on the inner diameter of the stone, the measured gas as well as the Reynolds number. However, the flowrate coefficient $\alpha$ is constant for a particular gas and type of stone in a certain range of Reynolds number Re. For example, for a stone with inner diameter $0.093 \mathrm{~mm}$ for the air for the number Re from 800 to 2000 the flowrate coefficient is 0.73 with an error $\pm 0.8 \%$, for a diameter of $0.113 \mathrm{~mm}$ and the number $R e$ from 800 to 2700 the flowrate coefficient is 0.77 with an error $\pm 1.3 \%$. The dependences of flowrate coefficient $\alpha$ on the number $R e$ and the expansibility factor $\varepsilon=f\left(m, \Delta P / P_{l}, \gamma\right)$ for the other non-standard constricting devices are presented in [14].

The flowrate characteristic of short capillary tubes belonging to combined throttle elements takes into account additional entrance and exit pressure losses and pressure losses for the forming a parabolic profile of velocities which is typical for the stable laminar flow. The dependence of the pressure drop across a short cylindrical tube on the mass flowrate of the Newtonian incompressible fluid is described by the Poiseuille equation with the corrections of Couette and Hagenbach [26]:

$$
\Delta P=\frac{128 Q \mu(L+n R)}{\rho \pi d^{4}}+m \frac{16 Q^{2}}{\rho \pi^{2} d^{4}}
$$

where $n$ is the Couette correction; $m$ is the Hagenbach correction. The exact experimental determination of the values of $m$ and $n$ is rather complicated and the known data is very contradictory. According to various researchers the coefficient $m$ varies from $1 / \sqrt{2}$ to 3.31 and the coefficient $n$ varies from 0 to 6 [27]. The imperfection of the model (29) is one of the reasons for such uncertainty of the coefficients $m$ and $n$, since the coefficient $n$ depends on the number $R e$. In turn, the uncertainty of the coefficients $m$ and $n$ is one of the main reasons for the low accuracy of mathematical models of throttle measuring transducers of dynamic viscosity [26], [27].

The following formulas are also used to describe the flowrate characteristic of capillary tubes of finite length [15]:

$$
\Delta P=\frac{128 Q \mu L}{\rho \pi d^{4}}+k \frac{16 Q^{2}}{\rho \pi^{2} d^{4}} \text { or } Q=\frac{4 \pi L \mu}{k}\left[\sqrt{1+\frac{k \rho d^{4} \Delta P}{256 L^{2} \mu^{2}}}-1\right]
$$

where $k$ is the empirical coefficient which depends on the capillary design, particularly on its ends, as well as the design of chambers between which the capillary is fixed. The coefficient $k$ also depends on the Reynolds number particularly due to the dependence of the entrance length on the number Re. This is the reason for the fact that according to various authors the coefficient $k$ in equation (30) varies widely [14], [27]. The other modifications of equation (30) are known too. Thus, in [27] for the tubes with a diameter of $0.5-2.5 \mathrm{~mm}$, length greater than $150 \mathrm{~mm}$ for the number Re from 100 to 2000 , the proposed equation is as follows:

$$
\Delta P=a \frac{4 Q \mu L}{\rho \pi d^{4}}+b \frac{16 Q^{2}}{\rho \pi^{2} d^{4}},
$$


where $a=34.39 \pm 0.83$ and $b=0.92 \pm 0.0084$ are the regression coefficients with the confidence probability of 0.95 . The results of calculating the pressure drop across the hydrodynamic throttles with typical dimensions for measuring transducers by equation (31) were compared with the calculation $\Delta P$ by the Hagen-Poiseuille equation (29) with the Hagenbach and Couette corrections. The relative error of calculating $\triangle P$ by equation (31) is less by $1-5 \%$ than by the formula (30) [27].

The equations for non-Newtonian fluids flow in tubes of finite length also contain a term $k \frac{16 Q^{2}}{\rho \pi^{2} d^{4}}$ which takes into account additional pressure losses for the formation of a velocity profile of the stabilized motion, the change in the fluid kinetic energy at the inlet and the outlet of the tube and the other factors in the same way as for the Newtonian fluid. Taking into account the equation (4) the flow of a power law liquid through a short capillary tube is described by the equation

$$
\Delta P=\left(\frac{8 Q}{\pi d^{3} \rho} \frac{3 n+1}{n}\right)^{n} \frac{4 L K}{d}+k \frac{16 Q^{2}}{\rho \pi^{2} d^{4}} .
$$

The coefficient $k$ decreases with smaller values of the flow behaviour index for a laminar flow of a power law liquid. Entrance losses for Bingham plastic fluids decrease with increasing values of the yield stress when the wall shear stress is constant. According to the research the entrance pressure losses for non-Newtonian fluids are usually higher that observed for Newtonian fluids [23]. equation

The flowrate characteristic for laminar flow of real gas through a short capillary tube is described by the

$$
Q=\frac{4 \pi L \mu}{k}\left[\sqrt{1+\frac{k d^{4} \rho_{N} T_{N}\left(P_{1}^{2}-P_{2}^{2}\right)}{512 L^{2} \mu^{2} Z T P_{N}}}-1\right],
$$

where the symbols correspond to the above equations (10)-(14). The adequacy of the model (33) was experimentally tested for glass capillary tubes with cylindrical channels of length $10 \ldots 300 \mathrm{~mm}$ and diameter $0.09 \ldots 0.3 \mathrm{~mm}$. The studies were carried out for the air within the pressure drop across a capillary tube from 10 to $160 \mathrm{kPa}$ at atmospheric pressure at the outlet of the tube [19]. The error of the flowrate determination by the equation (33) does not exceed $0.8 \%$, particularly for a tube of a diameter $0.1 \mathrm{~mm}$, a length $170.5 \mathrm{~mm}$ and the experimental coefficient $k$. The other research [14] shows that the error of the model (33) is within the range of 2-5\% if the corrections for the entrance losses are taken into account.

\subsection{Equations of fluid flow in microchannels}

Recently, much attention has been paid to the development of a variety of microdevices and microsystems with microchannel as the most important components. According to [42], tubes/channels of normal size have a diameter $d>3 \mathrm{~mm}$, minichannels $-200 \mu \mathrm{m}<d<3 \mathrm{~mm}$. Microchannels can be defined as the tubes with a diameter in the range of $10 \mu \mathrm{m}<d<200 \mu \mathrm{m}$. Transient microchannels have a diameter in the range of $1 \mu \mathrm{m}<d<10 \mu \mathrm{m}$, the transient nanochannels have a diameter in the range of $0.1 \mu \mathrm{m}<d<1 \mu \mathrm{m}$; the nanochannels have a diameter $d<0.1 \mu \mathrm{m}$. According to [29], [38], microchannels can be defined as tubes/channels whose hydraulic diameters are less than $1 \mathrm{~mm}$, but more than $1 \mu \mathrm{m}$. Microchannels offer the advantages due to their high surface-to-volume ratio and their small volumes [29].

The unique feature of microchannels is the existence of mostly laminar flow [38]. Experimental studies of the laminar flow of fluids in sufficiently long smooth microchannels of various shapes have shown that the pressure drop across them can be determined by the equations obtained for ordinary-sized capillaries in [31]. For single-phase fluid flow in smooth microchannels of hydraulic diameter from $15 \mu \mathrm{m}$ to $4010 \mu \mathrm{m}$, in the range of Reynolds number $R e<R e_{c r}$ the Poiseuille number $P o$ is independent of the Reynolds number $R e$. Experimental friction factor in laminar flow regime is in good agreement with the Hagen-Poiseuille theory for Reynolds number below 800-1000. For higher values of Reynolds number, experimental data depart from the Hagen-Poiseuille law to the side of higher values Poiseuille number [33]. The deviation within $10-20 \%$ can be explained by the discrepancy between the actual conditions of a given experiment and the assumptions used in deriving the theoretical value as well as the error in 
measurements [31]. According to experiments the critical Reynolds number $R e_{c r}$ is $1500-3800$ for the circular, rectangular, trapezoidal, square microchannels made of glass and silicon, plexiglass, stainless steel [31], [33].

Similar results are also obtained for high viscosity liquids [32]. The study of flow of glycerol aqueous solution in rectangular microchannel at $0.4<R e<40$ showed that the experimental friction factor is agreed with the value predicted by the conventional theory with consideration of the measurement uncertainty. So, for incompressible liquid in the isothermal conditions and fully developed laminar flow the Darcy friction factor $f_{D}$ calculated based on the NavierStokes equation is expressed as follows:

$$
f_{D}=\frac{96}{R e} \cdot\left(1-1.3553 a+1.9467 a^{2}-1.7012 a^{3}+0.9564 a^{4}-0.2537 a^{5}\right),
$$

where $a=h / w$ is the ratio of the dimension for the short side $h$ to that of the long side $w$ of the rectangular channel; $R e=\frac{2 Q}{\mu(w+h)}$ is the Reynolds number for the rectangular channel. The Darcy friction factor $f_{D}$ for the laminar flow in a circular channel is given by

$$
f_{D}=\frac{64}{R e} .
$$

Theoretical studies of gas flow in microchannels $[25,41]$ have shown that the flow behaviour for them cannot be described only using the assumptions adopted for describing the flow in ordinary-sized capillaries. The main differences between fluid mechanics at micro scales and in the macro domain can be broadly classified into four areas: Non-continuum effects, surface-dominated effects, low Reynolds number effects, and multi-scale and multi physics effects. Papers [28], [29] specify these differences and show that the small scale makes molecular effects such as wall slip more important and it amplifies the magnitudes of certain ordinary continuum effects to extreme levels. Accordingly, they take into account the non-zero velocity of sliding on the wall, the change in the temperature of the gas, and as a consequence of the change in viscosity, a significant change in density, and a number of other effects that vary in different ways on the flow characteristics. In particular for gas microflows pressure gradient becomes especially large in small cross-section channels and compressibility effects are very important because of relatively large density gradients, although the Mach number is typically low [28]. Fluids that are Newtonian at ordinary rates of shear and extension can become non-Newtonian at very high rates. Electrokinetic effects occur at the interface between liquids and solids such as glass due to chemical interaction [29].

In the works [25], [41] a two-dimensional solution for laminar flow of compressible Newtonian fluids in capillaries are theoretically obtained

$$
\Delta P=\frac{128 Q \mu L}{\rho_{2} \pi d^{4}}\left\{1-\left[\frac{1}{2}-\frac{1}{4} a \operatorname{Re}\right] \bar{\varepsilon}+\left[\frac{1}{2}-\frac{1}{2} a^{2}-\frac{1}{6} a^{2}\left(\chi+\frac{1}{3}\right)-\frac{1}{2} a \operatorname{Re}+\frac{1}{27}(a \operatorname{Re})^{2}\right] \bar{\varepsilon}^{2}+\mathrm{O}\left(\bar{\varepsilon}^{3}\right)\right\},
$$

where $a=(d / 2) / L$ is the ratio of the radius to the length of the circular channel; $R e=2 Q / \pi d \mu$ is one-half the conventional definition of Reynolds number; $\bar{\varepsilon}=\frac{128 \mu L Q}{\rho_{2} \pi d^{4}} \beta$ is the compressibility parameter; $\beta$ is the compressibility; $\chi$ is the bulk-to-shear viscosity ratio.

If we neglect terms $a^{2}$ and $a^{2}(\chi+1 / 3)$ in equation (36) then it will take the form

$$
\Delta P=\frac{128 Q \mu L}{\rho_{2} \pi d^{4}}\left(1-\frac{1}{2} \bar{\varepsilon}+\frac{1}{4} \bar{\varepsilon}(a R e)+\frac{1}{2} \bar{\varepsilon}^{2}-\frac{1}{2} \bar{\varepsilon}^{2}(a R e)+\frac{1}{27} \bar{\varepsilon}^{2}(a R e)^{2}+\cdots\right)
$$

The equation (37) predicts both a non-zero radial velocity and non-zero radial pressure gradient. Fluid inertia is responsible for the radial velocity. Bulk viscosity leads to a radial pressure gradient [25]. The first term in (37) form of the Hagen-Poiseuille equation, and the terms that follow give corrections due to fluid compressibility.

For sufficiently long microchannels the pressure drop calculated by the equation (37) for slow gas flows $(a R e<1$, $M a>0.1)$ is less than the pressure drop for a incompressible fluid. The smaller the capillary diameter and the greater 
the number $R e$, the more predictable decrease in the pressure drop is. For the subsonic high-speed flows $(a R e>1$, $0.1<M a<1)$ compressibility leads to a significant increase in the pressure drop compared with the incompressible flow. These trends are consistent with a large number of experimental studies on flows of compressed fluids in smooth microtubules and channels [25].

In the theoretical research [30] an equation is obtained for analysing the influence of the effects of compressibility and rarefaction on the local flow resistance of isothermal gas flow in circular microchannels:

$$
f_{F}(x)=\frac{16}{R e}\left(1+\frac{A}{-A+\sqrt{(1+A)^{2}-\gamma(64 / R e) M a^{2}(L / d) \bar{x}}}\right)^{-1},
$$

where $f_{F}$ is the local Fanning friction factor along the microchannel; $A=8 \frac{2-\sigma}{\sigma} \sqrt{\frac{\pi \gamma}{2}} \frac{M a}{R e}$ is the dimensionless coefficient; $M a=\frac{u}{\sqrt{\gamma R T}}$ is the inlet Mach number; $u$ is the inlet axial average velocity, $R e=4 Q / \pi d \mu$ is the inlet Reynolds number; $\bar{x}=x / L$ is the axial dimensionless coordinate; $L$ is the length of the channel; $\gamma$ is the specific heats ratio; $\sigma$ is the coefficient that indicates the influence of rarefaction and fluid-surface interaction, it is thought to vary between 0 and 1 depending on the surface roughness, temperature and gas type.

The equation (38) shows that the local Fanning friction factor across the microchannel is a function of the inlet Mach number, the Reynolds number and the length-diameter ratio of the channel. Calculations of the nitrogen flow in the microchannel carried out by the formula (38) showed that for a higher Reynolds number and a larger inlet Mach number the friction coefficient is higher than the value in macrotubes, the gas flow in the microchannel is dominated only by compressibility; while for a lower Reynolds number and a smaller inlet Mach number, the Fanning friction factor of gas flow in the microchannel is smaller than that in a circular tube with conventional size due to slip flow at the microchannel wall, clarifying that rarefaction has a significant effect on fluid flow characteristics. Model (38) agrees with the experimental data obtained in [35].

According to (38), the pressure drop in a circular microchannel can be determined by the formula

$$
\Delta P=\frac{128 Q \mu L}{\rho_{1} \pi d^{4}}\left(1-\frac{A}{\sqrt{(1+A)^{2}-\gamma(64 / R e) M a^{2}(L / d)}}\right) .
$$

The effects of molecular structure are quite different in gases and liquids. If the Knudsen number (defined as $K n=\lambda L_{s}$, where $\lambda$ is the mean free path in a gas and $L_{s}$ is the characteristic channel dimension) is greater than $10^{-3}$, non-equilibrium effects may start to occur. Molecular effects in liquids are difficult to predict because the transport theory is less well developed than the kinetic theory of gases. For this reason, studies of liquid microflows in which molecular effects may play a role are much more convincing if done experimentally [29].

In [31] particular, for single-phase gas flow in microchannels of hydraulic diameter from 101 to $4010 \mu \mathrm{m}$, in the range of Reynolds number $R e<R e_{c r}$, Knudsen number $0.001<K n<0.38$, Mach number $0.07<M a<0.84$, the experimental friction factor agrees quite well with the theoretical one predicted for fully developed laminar flow. The frictional resistance of gas flow in microtubes of diameter ranging 5 to $100 \mu \mathrm{m}$ was observed to be smaller than that in conventional sized tubes [34]. The reduced frictional resistance in microtubes seems to be caused by the compressibility effect due to a significant pressure drop along relatively short flow passages and rarefaction effect due to extremely small dimensions of flow passages.

As the diameter of microtubes decreases, the surface to volume ratio increases rapidly. As a result, the surface phenomena, including the effect of roughness, become more significant. In [44] a model was proposed for calculating the pressure drop in long microtubes with rough walls for the laminar flow of an incompressible fluid:

$$
\Delta P=\left\{\begin{array}{ll}
\frac{8 Q \mu L}{\rho \pi R^{4}}\left(\frac{1}{1-23 e^{2}}\right), & e \leq 0.1 \\
\frac{8 Q \mu L}{\rho \pi R^{4}}\left(\frac{1}{1-50 e^{2.4}}\right), & 0.1<e \leq 0.15
\end{array},\right.
$$


where $e=\sigma / R$ is the relative roughness defined as the root mean square wall roughness $\sigma$ over the radius $R$ of the microtube. According to the model (40) effect of roughness can be neglected if relative roughness is less than $3 \%$. The pressure drop increases with an increase in relative roughness compared with smooth microtubes. This fact is confirmed by simulation and experimental data [44]. It was found experimentally that the conventional laminar prediction is applied for gaseous flow in microchannels with a relative surface roughness less than $1 \%$. The friction factors in stainless steel microtubes are much higher than the theoretical predictions for tubes of conventional size. This discrepancy is resulted from the large relative surface roughness in the stainless steel tubes [35]. As a result it can be said that the pressure drop significantly increases (by more than 20\%) in the microchannels with sufficiently high roughness compared with smooth surfaces at the same Reynolds numbers. The existence of roughness leads also to decreasing the value of the number $R e_{c r}$, at which occurs transiting from laminar to turbulent flow [31].

The above equations of flowrate characteristics show that most of the throttle elements are nonlinear elements with the exception of the long hydraulic tube of an ordinary size. Therefore, any measuring diagram built on the throttle elements will have the properties predetermined by their nonlinearity.

Despite the fact that mathematical models of throttle elements of ordinary sizes are studied enough today and mathematical models of microchannels are being investigated intensively the measuring transducers with one throttle do not always ensure sufficient accuracy or sensitivity of measurement. So the measuring diagrams of the transducers are built mainly on several throttles in order to obtain the necessary metrological characteristics. Since the mathematical model of the throttle measuring diagram consists of a system of equations of material balances and a system of equations of the flowrate characteristics of throttle elements used in the diagram, the accuracy of the model of the throttle diagram will be mainly determined by the accuracy of the mathematical models of throttle elements. Therefore, the correct choice of mathematical models of throttle elements in the measuring diagram is the basis for obtaining adequate models of measuring transducers. The above equations of the flowrate characteristics of the throttle elements show that this choice depends on many factors: on fluid physical and mechanical properties and its structure, on its rheological behaviour, on the gas-hydrodynamic working conditions of each throttle in the diagram, on the constructive characteristics and throttle dimensions. Thus, mathematical models of throttle elements can be different even in the same diagram. Their own application conditions need to be taken into account while synthesizing the throttle measuring diagrams.

Thus, the analysis of the mathematical models of throttle elements is useful for computer research of static and metrological characteristics of measuring transducers built on throttle diagrams. It should be noted that it is necessary to use the new theoretical and regressive dependences to define the characteristics of fluids flow in microchannels for the effective design of microdevices.

\section{Conclusion}

The paper contains the review and the analysis of the flowrate characteristics of throttle elements as the main components of gas-hydrodynamic devices and measuring transducers of physical and mechanical parameters of fluids. The research performed by many authors for mathematical models of throttle elements of various types for gases and liquids with different rheological behaviour are systematized in the paper. Conditions for applying the flowrate characteristics for the flow of Newtonian and non-Newtonian liquids and gases in channels of various configurations and dimensions, including microchannels, are considered. The recommendations for their application to construct the measuring transducers of fluid parameters are proposed. Thus, the correct choice of mathematical models of throttle elements in the measuring diagram provide the adequate models of measuring transducers of specific physical and mechanical parameters. New theoretical and regressive dependences are systematized to determine the characteristics of fluid flow in microchannels and recommended for effective microdevices design. The obtained results are useful for computer research of static and metrological characteristics of gas-hydrodynamic devices and measuring transducers built on throttle diagrams.

\section{References}

[1] Profos, P., Pfeifer, T. (1994) Handbuch der Industriellen Meßtechnik. Wissenschaftsverlag, Oldenbourg.

[2] Webster, J., Eren, H. (2014) Measurement, Instrumentation, and Sensors Handbook: Spatial, Mechanical, Thermal, and Radiation Measurement, Second Edition, CRC Press Reference.

[3] Pistun, Ye. (1985) Theoretical Foundations for Constructing and Calculating Gas-Hydrodynamic Throttle Measuring Transducers. Abstracts of the XV All-Union Conference "Pnevmoavtomatika”, P.1, Lvov, 104-105. (in Russian) 
[4] Pistun, Ye., Leskiv, H. (2002) Gas-hydrodynamic Measuring Transducers Built on Complex Throttle Elements. Proc. of Lviv Polytechnic National University: Heat Power Engineering. Environmental Engineering. Automation, 460, 81-88. (in Ukrainian)

[5] Pistun, Ye., Krykh, H., Leskiv, H. (2003) Modeling of Gas-hydrodynamic Measuring Transducers Built on Bridge Throttle Schemes with Constant Flowrate. Scientific and technical journal "Methods and instruments of quality control", 10, 87-89. (in Ukrainian)

[6] Pistun, Ye., Matiko, H., Krykh, H., Matiko, F. (2018) Structural Modeling of Throttle Diagrams for Measuring Fluid Parameters. Metrology and Measurement Systems. 25(4), 659-673. DOI: 10.24425/mms.2018.124884

[7] Pistun E. P., Stasiuk I. D., Tepliukh Z. M. (1985) Investigation of Flowrate Curves of Capillary Elements of Measurement Instruments // Control and Measurement Instrumentation. 38, 44-46. (in Russian)

[8] Pistun, Ye., Matiko, H., Krykh, H. (2016) Modelling of Measuring Transducers Schemes Using Set Theory. Metrology and instruments, 3, 53-61. (in Ukrainian)

[9] Pistun, Ye., Matiko, H., Krykh, H., Matiko, F. (2017) Synthesizing the Schemes of Multifunctional Measuring Transducers of the Fluid Parameters. Eastern-European Journal of Enterprise Technologies, 6, 5(90), 13-22. https://doi.org/10.15587/1729-4061.2017.114110

[10] Poling, B., Prausnitz, J., O' Connell, J. (2000) The Properties of Gases and Liquids. McGraw-Hill Education.

[11] Zalmanzon, L. (1973) Aero-Hydrodynamic Methods for Measuring the Input Parameters of Automatic Systems. Science, Moscow. (in Russian)

[12] Ibragimov, I., Farzane, N., Ilyasov, L. (1985) Elements and Systems of Pneumatic Automation. Higher school, Moscow. (in Russian)

[13] Nagornyi, V. (2014) Means of Automation of Hydraulic and Pneumatic Systems. Tutorial. Publishing house "Lan". (in Russian)

[14] Kremlevskyi, P. (2002) Flowmeters and Meters of Substances. Publishing House "Polytechnic". (in Russian)

[15] Kabza, Z. (1981) Mathematical Modeling of Flowmeters with Constricting Devices. Mechanical Engineering, Leningrad. (in Russian)

[16] ISO 5167-1:2003. Measurement of Fluid Flow by Means of Pressure Differential Devices Inserted in Circular Cross-Section Conduits Running Full - Part 1: General Principles and Requirements.

[17] Pistun, Ye., Lesovoi, L. (2006) Standardization of Pressure Differential Flowmeters. CJSC "Institute of Energy Audit and Energy Resources", Lviv. (in Ukrainian)

[18] Pistun, Ye., Tepliukh, Z., Stasiuk, I. (1986) Flow Characteristics of Gas-Dynamic Throttle Elements. In Book: Pneumatic and Hydraulic Devices and Control Systems. X International Conference "Jablonna”, Energoatomizdat, 31-34. (in Russian)

[19] Stasiuk, I. (2015) Gas Dynamical Capillary Flowmeters of Small and Micro Flowrates of Gases, Energy Engineering and Control Systems, 1 (2), 117-126

[20] Tepliukh, Z., Pistun, Ye. (1978) Using Various Functional Dependencies to Describe Flow Characteristics of Turbulent Throttles, Measurement Techniques, 2, 231-234. (Translated from Izmeritel'naya Tekhnika, No. 2, pp. 48-50 by Plenum Publishing Corporation, February, 1977.)

[21] Gornstein, B. (1979) Determining of Gas Flow Through a Capillary, Metrology, 1, 66-74. (in Russian)

[22] Walicka, A. (2018) Flows of Newtonian and Power-Law Fluids in Symmetrically Corrugated Capillary Fissures and Tubes. Int. J. of Applied Mechanics and Engineering, 23 (1), 187-211. https://doi.org/10.1515/ijame-2018-0011

[23] Steffe, J. (1996) Rheological Methods in Food Process Engineering, USA, Freeman Press.

[24] Krykh, H. (2008) Mathematical Models of Throttle Elements of Hydrodynamic Measuring Transducers of Non-Newtonian Liquid Parameters. Proc. of Lviv Polytechnic National University: Heat Power Engineering. Environmental Engineering. Automation, 617, 122129. (in Ukrainian)

[25] Venerus, D. (2006) Laminar Capillary Flow of Compressible Viscous Fluids. Journal Fluid Mechanics, 555, 59-80. https://doi.org/10.1017/S0022112006008755

[26] Malkin, A., Isayev, A. (2017) Rheology: Concepts, Methods and Applications. Chemical Technology Publishing House.

[27] Drevetskyi, V. (2012) Mathematical Models of Throttle Transducers for Hydrodynamic Measuring Devices of Viscosity and Density of Liquids. Methods and Instruments of Quality Control, 29, 38-46. (in Ukrainian)

[28] Karniadakis, G., Beskok, A., Aluru, N. (2002) Microflows. Fundamentals and Simulation.

[29] Sharp, K., Adrian, R., Santiago, J., Molho, J. (2005) MEMS: Background and Fundamentals. Chapter 10: Liquid Flows in Microchannels, $10-1-10-45$.

[30] Cao, B., Chen, G., Li, Y., Yuan, Q. (2006) Numerical Analysis of Isothermal Gaseous Flows in Microchannel. Chemical Engineering Technology, 29 (1), 66-71. https://doi.org/10.1002/ceat.200407079

[31] Hetsroni, G., Mosyak, A., Pogrebnyak, E., Yarin, L. (2005) Fluid Flow in Micro-Channels International. Journal of Heat and Mass Transfer, 48, 1982-1998. DOI: 10.1016/j.ijheatmasstransfer.2004.12.019

[32] Guangwen, Y., Yuan, Ch. (2014) Effect of Viscosity on the Hydrodynamics of Liquid Processes in Microchannels. Chemical Engineering Technology, 37 (3), 427-434. https://doi.org/10.1002/ceat.201300468

[33] Bucci, A., Celata, G., Cumo, M., Serra, E., Zummo, G. (2003) Water Single-Phase Fluid Flow and Heat Transfer in Capillary Tubes. Conference ASME 2003, 1st International Conference on Microchannels and Minichannels, 319-326. doi:10.1115/ICMM2003-1037

[34] Kim, M., Araki T., Inaoka, K., Suzuki, K. (2000) Gas Flow Characteristics in Microtubes. JSME International Journal Series B, 43 (4),634 639. https://doi.org/10.1299/jsmeb.43.634

[35] Tang, G., Li, Zh., He, Y., Tao, W. (2007) Experimental Study of Compressibility, Roughness and Rarefaction Influences on Microchannel Flow. International Journal of Heat and Mass Transfer, 50, 2282-2295. DOI: 10.1016/j.ijheatmasstransfer.2006.10.034

[36] Taliadoroua, E., Georgioua, G., Moulitsas, I. (2009) Weakly Compressible Poiseuille Flows of a Herschel-Bulkley Fluid. Journal NonNewtonian Fluid Mechanics, 158, 162-169. DOI: 10.1016/j.jnnfm.2008.11.010 
[37] Liu, D., Garimella, S. (2004) Investigation of Liquid Flow in Microchannels. AIAA Journal of Thermophysics and Heat Transfer. 18 (1), 6572. https://doi.org/10.2514/1.9124

[38] Obot, N. (2000) Toward a Better Understanding of Friction and Heat/Mass Transfer in Microchannels - A Literature Review. United Engineering Foundation Conference, Heat Transfer and Transport Phenomena in Microsystems, Oct. 15-20, 2000, Banff, Alberta, 1-8.

[39] Harley, J., Huang, Y., Bau, H., Zemel, J. (1994) Gas Flow in Micro-Channels. Journal of Fluid Mechanics, 284, $257-274$. http://dx.doi.org/10.1017/S0022112095000358

[40] Cai, Ch., Sun, Q., Boyd, I. (2007) Gas Flows in Microchannels and Microtubes. Fluid Mechanics, 589, 305-314. https://doi.org/10.1017/S0022112007008178

[41] Taliadoroua, E., Neophytou, M., Georgiou, G. (2009) Perturbation Solutions of Poiseuille Flows of Weakly Compressible Newtonian Liquids, Journal of Non-Newtonian Fluid Mechanics, 163, 1-3, 25-34. https://doi.org/10.1016/j.jnnfm.2009.06.003

[42] Teng, J., Chu, J., Yu, X., Dang, Th., Lee, M. et al. Fluid Dynamics, Computational Modeling and Applications. Chapter - Fluid Dynamics in Microchannels, 403-436.

[43] Zhang, X., Zhu, W., Cai, Q., Shi, Y. Wu, X. Jin, T. Yang, L., Song, H. (2018) Compressible Liquid Flow in Nano- or Micro-Sized Circular Tubes Considering Wall-Liquid Lifshitz-Van Der Waals Interaction. Physics of Fluids, 30, 062002. https://doi.org/10.1063/1.5023291

[44] Bahrami, M., Yovanovich, M. and Culham, J. (2005) Pressure Drop of Fully Developed, Laminar Flow in Rough Microtubes. Journal of Fluids Engineering, 128 (3), 632-637. doi:10.1115/1.2175171

[45] Silva, G., Leal, N. Semião, V. (2008) Effect of Wall Roughness on Fluid Flow Inside a Microchannel. 14th Int Symp on Applications of Laser Techniques to Fluid Mechanics, Lisbon, Portugal, 07-10 July, 2008, 1-12.

[46] Celata, G., Cumo, M., McPhail, S., Tesfagabir, L., Zummo, G. (2007) Experimental Study on Compressible Flow in Microtubes. International Journal of Heat and Fluid Flow, 28, 28-36. https://doi.org/10.1016/j.ijheatfluidflow.2006.04.009

[47] Mortensen, N., Okkels, F., Bruus, H. (2005) Reexamination of Hagen-Poiseuille flow: Shape Dependence of the Hydraulic Resistance in Microchannels. Physical Review, E. Statistical Nonlinear and Soft Matter Physics, 71(5), 057301, 1-5. doi:10.1103/PhysRevE.71.057301

[48] Bulhakov, B., Kubrak, A. (1977) Pneumatic Automation, Tehnika, Kyjiv. (in Russian)

[49] RD 50-411-83. (1984) Methodical Instructions. Flowrate of Liquids and Gases. Technique for Measuring Using Special Constricting Devices. Publishing House of Standards, Moscow. (in Russian)

[50] Pistun, Ye., Teplykh, Z., Stasyuk, I. (1984) Watch Jewels in Gas Microflow Measurement, Measurement Techniques, 11, 929-931 (Translated from Izmeritel'naya Tekhniya, No. 11, pp. 36-38 by Plenum Publishing Corporation, November, 1983.)

\title{
Математичні моделі дросельних елементів газогідродинамічних вимірювальних перетворювачів
}

\author{
Євген Пістун, Галина Матіко, Ганна Крих \\ Національний університет «Львівська політехніка», вул. Степана Бандери 12, м. Львів, 79013, Україна
}

\section{Анотація}

В статті наведені витратні характеристики дросельних елементів, які застосовують у вимірювальних схемах перетворювачів параметрів плинних середовищ. Огляд включає широке коло досліджень характеристик нестискуваних та стискуваних, ньютонівських та неньютонівських середовищ в умовах ламінарного, перехідного та турбулентного режиму руху в каналах різного поперечного перерізу. Розглянуто рівняння, що застосовуються для макроскопічних потоків. Наведено теоретичні рівняння для розрахунку перепаду тиску під час руху середовищ у мікроканалах та зазначено умови та діапазон їх застосування. Розглянуто експериментальні результати дослідження коефіцієнтів тертя для стискуваних і нестискуваних середовищ в мікроканалах різних розмірів та форми, з гладкими і шорсткими поверхнями. Отримані результати можна застосовувати для комп'ютерного дослідження статичних і метрологічних характеристик газогідродинамічних вимірювальних перетворювачів конкретних фізико-механічних параметрів.

Ключові слова: витратна характеристика; капілярна трубка; пристрій звуження; мікроканал; вимірювальний перетворювач; фізико-механічні параметри. 